\title{
KIN Dental - the choice of professionals, now available in the UK
}

The KIN Dental range offers a vast range of differentiated, effective and safe products that are highly credited by both dental professionals and consumers and we are delighted to announce that KIN is now available to purchase in the UK.

\section{Passion, talent, commitment and} innovation

The success of KIN Dental products is owed to the consistent and determined researchers at KIN Laboratories since 1964 and we have continued to become pioneers in innovative dental products ever since. With a large diverse offering of products for general dentistry, dental hygienists, dental therapists, periodontists, orthodontists and dental surgeons, to name a few, KIN products have become the partner of choice for dental professionals to help their patients receive effective and long-lasting results.

\section{Globally recognised}

Today, KIN is a globally recognised and a trusted brand in the oral care and dental market. KIN values and philosophies are shared in over 60 countries worldwide and we are delighted to extend our commitment to the UK market.

\section{PerioKIN Hyaluronic 1\%}

Our newest addition to the range is PerioKIN Hyaluronic $1 \%$. This is an innovative dental gel with $1 \%$ Hyaluronic Acid and $0.20 \%$ Chlorhexidine DG. It has the highest hyaluronic acid concentration in any dental-based gel and it's the $1 \%$ that makes the difference. Application of PerioKIN Hyaluronic $1 \%$ provides a beneficial effect in terms of healing in the first 24-48 hours post-application. It also provides greater bio adhesiveness. For use in oral hygiene in the case of:
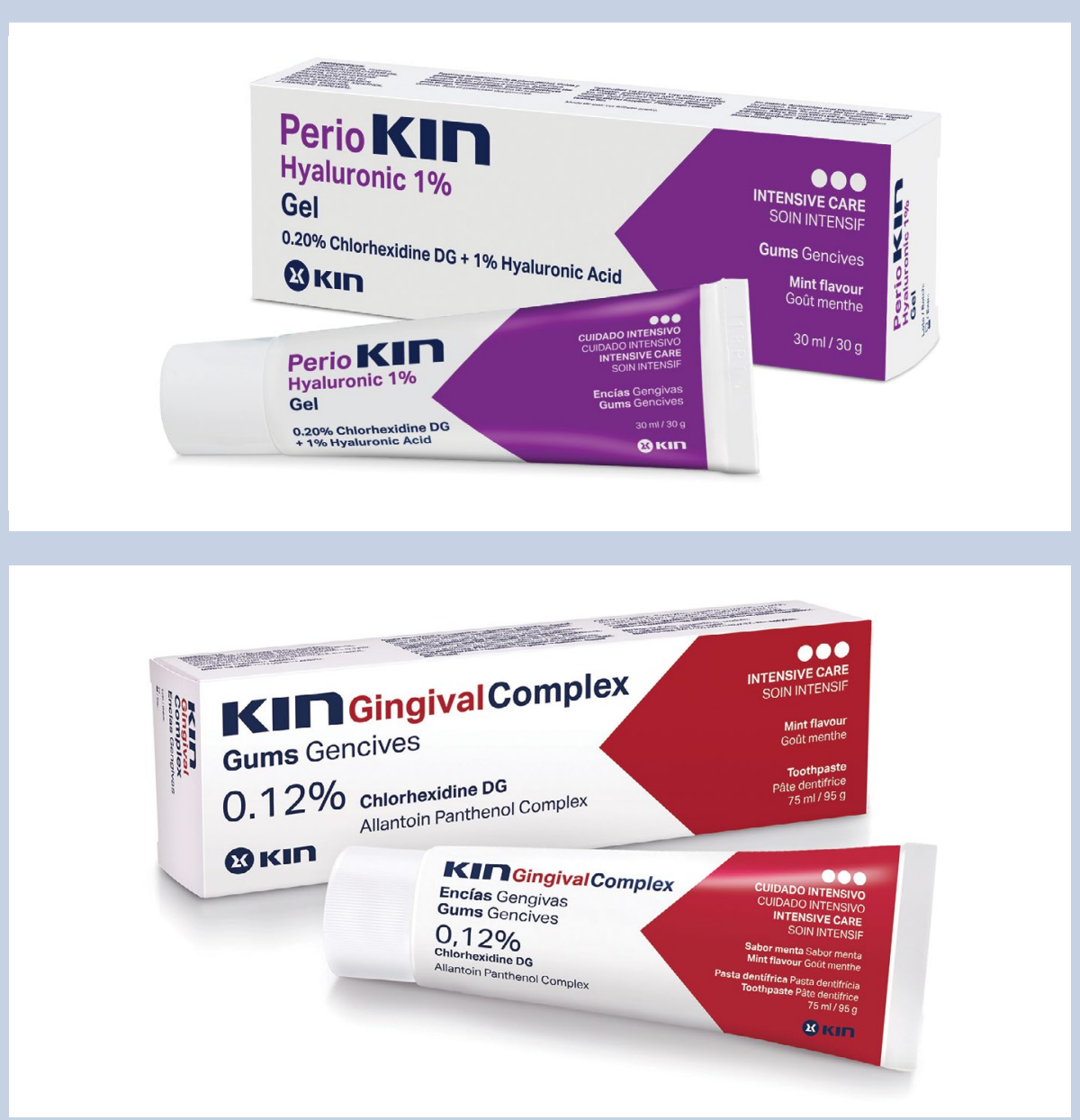

- Post-extraction

- Post-surgery

- Implants

- Pericoronitis or periodontitis.

\section{KIN gingival complex}

Patented formula that combines the toning and moisturising effect with the anti-plaque efficacy. Containing Chlorhexidine DG $0.12 \%$, the gold standard antiplaque agent Cetylpyridinium Chloride (CPC) $0.05 \%$, broad-spectrum anti-plaque agent Alpantha Complex offering a moisturising effect on gingival tissues.

Alpantha complex is a functional compound comprised of Allantoin and Panthenol. Both Allantoin and Panthenol have properties that stimulate cell regeneration and proliferation. However, by acting in a synergistic manner in the Alpantha complex, their properties are maximised. Allantoin will make the stratum corneum more permeable, so that Panthenol penetrates the stratum basale in a more efficacious and fast way, where it will exert its moisturising and toning action.

\section{KIN B5}

The accumulation of dental biofilm is mainly responsible for gingival pathology (inflammation and bleeding of the gums). It is therefore very important to use specific products on a daily basis that control dental plaque and strengthen the gums. KIN B5 contains Cetylpyridinium Chloride (CPC), zinc lactate, Provitamin B5, Vitamin B3, Xylitol $1.00 \%$ and sodium fluoride.

\section{Available in the UK}

KIN offer a dedicated training team for the UK market, who are available to demonstrate the benefits of each of the products and speak to you about how KIN products can add value to your practice and to your patients. If you would like to speak to one of our UK Reps or for more information on KIN go to www.kindental.co.uk or contact us on info@kindental.co.uk. 